\title{
Liaison conference for adolescent psychosomatic disease in pediatric ward
}

\author{
Takuji Inagaki ${ }^{1}$, Rei Wake ${ }^{2}$, Kazuko Kishi ${ }^{3}$ \\ ${ }^{1}$ Department of Psychology and Special Support Education, Faculty of Education, Shimane University, Matsue, Japan \\ ${ }^{2}$ Department of Psychiatry, Faculty of Medicine, Shimane University, Izumo, Japan \\ ${ }^{3}$ Department of Pediatrics, Faculty of Medicine, Shimane University, Izumo, Japan \\ Email: inagaki@edu.shimane-u.ac.jp
}

Received 29 November 2011; revised 30 December 2011; accepted 11 January 2012

\begin{abstract}
We held the liaison case conferences for two adolescent cases with psychosomatic disease in the pediatric ward to understand the patient's emotional problems and family situations, and to discuss how approach their psychological problems. We considered that the liaison conference played a useful role in both the clinical diagnosis and treatment. Furthermore, the liaison conference was useful for reducing the staff's anxieties and for contributing to have a proper understanding for the disease. We suggest that a liaison conference should be implemented in pediatric units, for pediatric patients with emotional and behavioral problems.
\end{abstract}

Keywords: Conference; Consultation Liaison Psychiatry; Pediatrics; Pediatric Ward; Psychosomatic Disease

\section{INTRODUCTION}

Consultation liaison psychiatry has been recognized as an important part of general hospital psychiatry [1,2]. Psychiatrists are often asked by physicians to evaluate and treat patients. Psychiatrists usually participate in clinical conferences and communicate their diagnosis and treatment plan to the physicians in the wards.

We have conducted liaison conferences in the pediatric ward of our hospital since 1999. There have been few reports with liaison conference in pediatric ward. Therefore we report two cases of psychosomatic diseases and discuss the significance of liaison conferences in pediatric ward.

\section{CASE REPORT}

Case 1: A 14 year-old-boy was admitted to the pediatric ward in our hospital because of appetite loss and general fatigue in 20xx. He had been anxious about his mother's psychiatric condition (bipolar disorder) and had been bul- lied by an older student at school. The patient refused to attend school. He was examined physically and showed no marked abnormalities and pediatricians diagnosed his symptoms as psychosomatic disease with psychological factors and referred him to us 5 weeks after his admission. We counseled him 25 times during his 6 months admission. His admission was prolonged and the nursing staff were also anxious about his prolonged symptoms. Moreover the pediatrician felt the patient's treatment had come to an impasse. Therefore, two liaison conferences were held in the pediatric ward. The proposer of the conferences was the pediatrician and the participants included the pediatrician, a chief nurse, nurses in charge, teachers of a class in hospital and a psychiatrist. We discussed the patient's psychological and physical conditions and shared the following information among us: the patient was worried about his mother's condition; worried about the progress of lessons of school; and upset by his father's expectation that he should be strong in the face of adversity. The nursing staff were also not coincident for his care plans and anxious about his prognosis.

At the conference a therapeutic plan was constructed; we advised the patient to speak his mind to staff and to separate his disease from his mother's illness. We advised his parents to meet him together, and we interviewed his father several times. Staff repeatedly advised his parents to be openly accepting of their son. As a result the patient was gradually able to talk to the nursing staff about his anxieties in returning to school. Subsequently, the patient's symptoms disappeared and he was discharged from the hospital and could attend school again.

Case 2: A 14 year-old girl was admitted to the pediatric ward with headache, gastralgia and general fatigue in 20xx. She complained of headache and abdominal pain, and had stopped going to school prior to being admitted because trouble with her friends, after which gastralgia worsened and general fatigue developed. The patient was admitted to our hospital for three weeks and discharged when her symptoms improved. However, she developed gastralgia again and was readmitted two months later. 
She was examined physically and showed no abnormal lesions and the pediatrician diagnosed her with psychosomatic gastritis and referred her to the psychiatric division 4 weeks after her second admission. We counseled her 24 times during her 5.5 months admission. Since her symptoms were prolonged without a clear therapeutic plan, liaison conferences were held four times in the pediatric ward. The proposer of the conferences was a pediatrician every time, and the participants consisted of a pediatrician, psychiatrist, a chief nurse, nurse in charge and the patient's parents. In the conferences, the following facts were revealed: the patient did not wish to return to junior high school or enter high school. However, her parents expressed a strong desire for her to enter high school; thus, there was a conflict between her and her parents. Furthermore, the patient found it difficult to confide her feelings of conflict in other people and felt confused. We discussed the patient's psychological background and shared information. At the conferences therapeutic plan was constructed; we encouraged the patient to express her emotional feelings and worries and advised her parents to accept their daughter's decisions. The patient ultimately decided to start a high school correspondence course, and was discharged from our hospital with no abnormal symptoms.

\section{DISCUSSION}

We herein reported two adolescent patients with psychosomatic diseases who refused to attend school. Both patients were hospitalized for a long time and on physical examination showed no marked abnormalities. The pediatricians diagnosed them with psychosomatic diseases with psychological factors and referred them to a psychiatrist for counseling. Liaison conferences were held more than twice per case in the pediatric ward to understand the patient's emotional problems and family situations, and to discuss how to approach their psychological problems. Participants consisted of a psychiatrist, pediatriccians, a chief nurse, nurses in charge, teachers of a class in hospital and occasionally the patient's parents (Figure 1).

In the conferences, we were better able to grasp both the patient's physical and mental status, and also build a clear picture of the patient's daily life. Furthermore, we could unify the treatment plans and divide the steps for the therapeutic goal among staff. The nursing staff were anxious about the patient's prolonged symptoms. Therefore the liaison conference was useful for reducing the staff's anxieties and for contributing to have a proper understanding for the disease. The inclusion of a psychiatrist has been emphasized as contributing to staff support, education and research [3]. Furthermore we considered that the participation of parents in the conference was effective for better understanding of the psychosomatic causes of the patient's complaints.

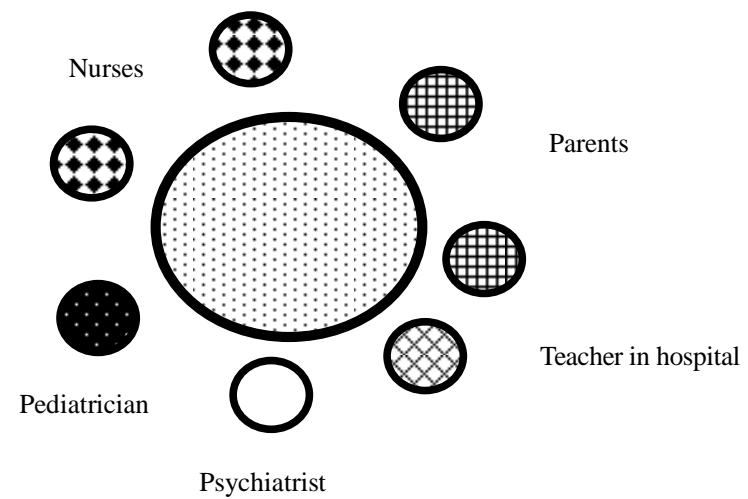

Participants usually consist of a psychiatrist, a pediatrician, a chief nurse, nurses in charge, a teacher of a class in hospital and occasionally the patient's parents.

Figure 1. Liaison conference in pediatric ward.

We considered that the liaison conference played a useful role in both the clinical diagnosis and treatment of adolescent patients with psychosomatic diseases in the pediatric wards.

Consultation liaison psychiatry in child psychiatry emphasizes the importance of the emotional and behavioral needs of children in pediatric settings, and assists with adaptation and stress management within families who care for chronically ill children [4]. Burket R.C. et al. [5] reported that many pediatricians expected to refer patients for psychiatric consultation for emotional problems and adverse family situations. Moreover, adolescents were the patient group most frequently referred and behavioral problems were the most frequent reasons for consultation.

\section{CONCLUSION}

We suggest that a liaison conference should be implemented in pediatric units, for pediatric patients with emotional and behavioral problems.

\section{REFERENCES}

[1] Hall, R.C. and Frankel, B.L. (1996) The value of consultation-liaison interventions to the general hospital. Psychiatric Services, 47, 418-420.

[2] Mayou, R.A. (1997) Psychiatry, medicine and consultation-liaison. The British Journal of Psychiatry, 171, 203204. doi:10.1192/bjp.171.3.203

[3] Chan, S. (1996) Child psychiatric consultation and liaison in pediatrics. Singapore Medical Journal, 37, 194-196.

[4] Knapp, P.K. and Harris, E.S. (1998) Consultation-liaison in child psychiatry: A review of the past ten years. Part 1: Clinical findings. Journal of the American Academy of Child and Adolescent Psychiatry, 37, 17-25. doi:10.1097/00004583-199801000-00012

[5] Burket, R.C. and Hodgin, J.D. (1993) Pediatricians' perceptions of child psychiatry consultation. Psychosomatics, 34, 402-408. doi:10.1016/S0033-3182(93)71843-5 